\title{
The Protective Effect of Oral Application of Corni Fructus on the Disorders of the Cornea, Conjunctiva, Lacrimal Gland and Retina by Topical Particulate Matter 2.5
}

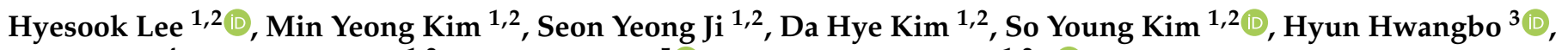 \\ Cheol Park ${ }^{4}$, Su Hyun Hong ${ }^{1,2}$, Gi-Young Kim ${ }^{5}$ and Yung Hyun Choi ${ }^{1,2, *(\mathbb{D})}$ \\ 1 Department of Biochemistry, College of Korean Medicine, Dong-Eui University, Busan 47227, Korea; \\ 14769@deu.ac.kr (H.L.); ilytoo365@deu.ac.kr (M.Y.K.); 14602@deu.ac.kr (S.Y.J.); \\ believe0402@naver.com (D.H.K.); 14731@deu.ac.kr (S.Y.K.); hongsh@deu.ac.kr (S.H.H.) \\ 2 Anti-Aging Research Center, Dong-Eui University, Busan 47340, Korea \\ 3 Korea Nanobiotechnology Center, Pusan National University, Busan 46241, Korea; hbhyun2003@naver.com \\ 4 Department of Molecular Biology, College of Natural Sciences, Dong-Eui University, Busan 47340, Korea; \\ parkch@deu.ac.kr \\ 5 Department of Marine Life Science, Jeju National University, Jeju 63243, Korea; immunkim@jejunu.ac.kr \\ * Correspondence: choiyh@deu.ac.kr; Tel.: +82-51-890-3319
}

\section{check for} updates

Citation: Lee, H.; Kim, M.Y.; Ji, S.Y.; Kim, D.H.; Kim, S.Y.; Hwangbo, H.;

Park, C.; Hong, S.H.; Kim, G.-Y.; Choi, Y.H. The Protective Effect of Oral Application of Corni Fructus on the Disorders of the Cornea, Conjunctiva, Lacrimal Gland and Retina by Topical Particulate Matter 2.5. Nutrients 2021 13, 2986. https://doi.org/10.3390/ nu13092986

Academic Editor: Elizabeth J. Johnson

Received: 27 July 2021

Accepted: 25 August 2021

Published: 27 August 2021

Publisher's Note: MDPI stays neutral with regard to jurisdictional claims in published maps and institutional affiliations.

Copyright: (c) 2021 by the authors Licensee MDPI, Basel, Switzerland. This article is an open access article distributed under the terms and conditions of the Creative Commons Attribution (CC BY) license (https:// creativecommons.org/licenses/by/ $4.0 /)$.

\begin{abstract}
Particulate matter $2.5\left(\mathrm{PM}_{2.5}\right)$ may aggravate dry eye disease (DED). Corni Fructus (CF), which is fruit of Cornus officinalis Sieb. et Zucc., has been reported to have various beneficial pharmacological effects, whereas the effect of CF on the eye is still unknown. Therefore, in this study, we investigated the effect of oral administration of water extract of CF (CFW) on the eye, hematology, and biochemistry in a DED model induced by topical exposure to $\mathrm{PM}_{2.5}$. Furthermore, the efficacy of CFW compared with cyclosporine (CsA), an anti-inflammatory agent, and lutein, the posterior eye-protective agent. Sprague-Dawley rats were topically administered $5 \mathrm{mg} / \mathrm{mL}$ $\mathrm{PM}_{2.5}$ in both eyes four times daily for 14 days. During the same period, CFW $(200 \mathrm{mg} / \mathrm{kg}$ and $400 \mathrm{mg} / \mathrm{kg})$ and lutein $(4.1 \mathrm{mg} / \mathrm{kg})$ were orally administered once a day. All eyes of rats in the $0.05 \%$ cyclosporine A (CsA)-treated group were topically exposed to $20 \mu \mathrm{L}$ of CsA, twice daily for 14 days. Oral administration of CFW attenuated the $\mathrm{PM}_{2.5}$-induced reduction of tear secretion and corneal epithelial damage. In addition, CFW protected against goblet cell loss in conjunctiva and overexpression of inflammatory factors in the lacrimal gland following topical exposure to $\mathrm{PM}_{2.5}$. Furthermore, CFW markedly prevented $\mathrm{PM}_{2.5}$-induced ganglion cell loss and recovered the thickness of inner plexiform layer. Meanwhile, CFW treatment decreased the levels of total cholesterol and low-density lipoprotein cholesterol in serum induced by $\mathrm{PM}_{2.5}$. Importantly, the efficacy of CFW was superior or similar to that of CsA and lutein. Taken together, oral administration of CFW may have protective effects against $\mathrm{PM}_{2.5}$-induced DED symptoms via stabilization of the tear film and suppression of inflammation. Furthermore, CFW may in part contribute to improving retinal function and lipid metabolism disorder.
\end{abstract}

Keywords: Corni Fructus; cyclosporine A; dry eye disease; goblet cells; lutein; particulate matter 2.5; retinal ganglion cells; tear production

\section{Introduction}

Air pollution is a serious health issue and consists of thousands of solid particles, gases, and liquid droplets [1]. Among the various biologically toxic substances of air pollutants, particulate matter 2.5 is considered the most important harmful substrate of health threat [2]. $\mathrm{PM}_{2.5}$ refers to particulate matter with diameter less than $2.5 \mu \mathrm{m}$ [2]. Several epidemiological and biochemical studies have shown that chronic or acute exposure to $\mathrm{PM}_{2.5}$ may be attributed to dry eye disease (DED), also known as keratoconjunctivitis sicca [3-7]. DED is a multifactorial disease of the ocular surface that involves tear film instability, 
hyperosmolarity, inflammation, and damage to the ocular surface [8,9]. Some studies have reported that people with exposure to severe air pollution often experienced symptoms of DED $[6,10,11]$. DED symptoms can include foreign body sensation, redness, stinging, pain, and burning on the eyes $[6,10,11]$. In rodents, studies have recently reported that topical exposure to $\mathrm{PM}_{2.5}$ results in the pathological events of DED, and these ocular changes are similar to those in humans [12-14]. Some cell-based studies have demonstrated that $\mathrm{PM}_{2.5}$ induces cytotoxicity, DNA damage, inflammation, and wound healing suppression in corneal epithelial and conjunctival epithelial cells [15-17]. Although air pollution is closely linked to pathogenesis of the ocular system, studies on the harmful effect of $\mathrm{PM}_{2.5}$ on the eye and the development of a therapeutic agent are still in the early stage.

The Oriental herbal medicine Corni Fructus (CF), which is fruit of Cornus officinalis Sieb. et Zucc., has been widely used to treat kidney deficiency, dizziness, spermatorrhea, pain, and hypertension for over 2000 years in eastern Asia [18,19]. Numerous studied have reported that extract of CF has various pharmacological benefits, including anticancer, anti-inflammation, neuroprotection, and anti-oxidative effects [20-24]. In addition, we previously demonstrated that CF inactivated $5 \alpha$-reductase and androgen receptor, consequentially resulting in suppression of testosterone propionate-induced benign prostatic hypertrophy [25]. More recently, it has been reported that CF protected human $\mathrm{HaCaT}$ keratinocytes against $\mathrm{PM}_{2.5}$-induced oxidative stress through suppression of $\mathrm{Ca}^{2+}$ accumulation and apoptosis [26]. Furthermore, several reports suggested that bioactive components from $\mathrm{CF}$, such as terpenoids, flavonoids, tannins, and furans, exhibit anti-inflammatory, anti-oxidative, and anti-apoptotic activities [27-29]. Recently, we also demonstrated that loganin and morroniside, major iridoid glycosides isolated from $\mathrm{CF}$, suppressed lipopolysaccharide-induced inflammation and oxidative response through activation of the nuclear factor erythroid 2-related factor 2/heme oxygenase-1 signaling pathway in RAW264.7 macrophages [27,30]. Despite reports that CF has various beneficial pharmacological effects, the effect of CF on the eye is still unknown. Therefore, in this study, we investigated the effect of oral administration of water extract of CF (CFW) on histological changes in the eye, including the cornea, conjunctiva, lacrimal gland, and retina, and on the changes in hematology and biochemistry in dry eye rat models induced by topical exposure to $\mathrm{PM}_{2.5}$. Furthermore, we evaluated the efficacy of CFW compared with lutein and cyclosporine A (CsA). Lutein is one of the xanthophyll carotenoids and has eye-protective properties [31], and CsA, an anti-inflammatory and a T cell immunomodulatory agent, is used to suppress ocular surface inflammation and improve tear film dynamics $[32,33]$.

\section{Materials and Methods}

\subsection{Preparation of $P M_{2.5}$ and Treatments}

The National Institute of Standards and Technology (NIST, Gaithersburg, MD, USA) SRM $1650 \mathrm{~b}$ standard diesel $\mathrm{PM}_{2.5}$ and spermidine were purchased from Sigma-Aldrich Chemical Co. (St. Louis, MO, USA). A $25 \mathrm{mg} / \mathrm{mL}$ stock solution of $\mathrm{PM}_{2.5}$ was prepared in dimethylsulfoxide (Invitrogen, Carlsbad, CA, USA) and diluted to the $5 \mathrm{mg} / \mathrm{mL}$ of $\mathrm{PM}_{2.5}$ in distilled water. The dried fruits of CF were provided by Gurye Sansuyu Farming Association Corporation (Jeollanam-do Province, Republic of Korea), and CFW was prepared according to a previous study [25]. CFW was diluted to the required concentrations in distilled water immediately before use. Lutein was obtained from Solgar (Leonia, NJ, USA). Topical CsA (0.05\% Cyporin $\mathrm{N}^{\circledR}$ eye drops) was obtained from Taejoon Pharma Co., Ltd. (Seoul, Korea).

\subsection{Animals and Experimental Procedures}

Animal care and all experiments were performed in accordance with the Guide for Animal Experimentation of Dong-eui University with the approval of the Institutional Animal Care and Use Committee (IACUC approval No. R2019-005). Six-week-old female Sprague-Dawley (SD) rats were obtained from Samtako Bio Korea Co. (Osan, Korea) and housed in a semi-pathogen-free facility with a temperature of $22-24{ }^{\circ} \mathrm{C}$, relative humidity 
of 50-60\%, and $12 \mathrm{~h}$ light/12 h dark cycles. After acclimatization for a week, the rats were randomly divided into six groups: untreated control group (Control, $n=5$ ); $\mathrm{PM}_{2.5}$-induced DED group (DED, $n=5$ ); $\mathrm{PM}_{2.5}$ with $200 \mathrm{mg} / \mathrm{kg}$ CFW group (CFW 200, $n=5$ ); $\mathrm{PM}_{2.5}$ with $400 \mathrm{mg} / \mathrm{kg}$ CFW group (CFW 400, n=5); $\mathrm{PM}_{2.5}$ with $4.1 \mathrm{mg} / \mathrm{kg}$ lutein group (Lutein, $n=5$ ), and $\mathrm{PM}_{2.5}$ with CsA group (CsA, $\left.n=5\right)$. DED was induced by topically administering $20 \mu \mathrm{L}$ of $5 \mathrm{mg} / \mathrm{mL} \mathrm{PM}_{2.5}$ in both eyes four times daily for 14 days, except for the control group. During the same period, CFW and lutein were administered orally once a day for 14 days. All eyes of rats in the CsA group were topically exposed to $20 \mu \mathrm{L}$ of CsA, twice daily for 14 days. Body weight was measured at baseline and on day 14 . The rats in all the groups were euthanized on day 14. After midline thoracotomy, whole blood and serum were prepared as previously described [34]. The left ventricle was catheterized using a 23-gage butterfly needle (Becton Dickinson, Franklin Lakes, NJ, USA), the femoral artery was incised and perfused with sterile saline at the rate of $10 \mathrm{~mL} / \mathrm{min}$ for $3 \mathrm{~min}$. After perfusion, the organs were immediately excised and weighed. The eyes and adnexa were dissected and fixed in 10\% formalin for histological and immunohistochemical analyses.

\subsection{Hematological and Biochemical Analysis}

Red blood cell (RBC) count, white blood cell (WBC) count, hematocrit, hemoglobin levels, mean corpuscular volume (MCV), mean corpuscular hemoglobin (MCH) levels, $\mathrm{MCH}$ concentration (MCHC), and platelet count were measured using a Sysmex XN9000 analyzer (Sysmex Corporation, Kobe City, Hyogo Prefecture, Japan). Serum alanine aminotransferase, aspartate aminotransferase, alkaline phosphatase, blood urea nitrogen, creatinine, and lipid profiles were analyzed using Cobas 8000 C702 chemistry analyzer (Roche, Mannheim, Germany).

\subsection{Tear Production}

On days 0,7 , and 14 post-treatment, tear volume was measured using phenol red tear threads (Jingming Ltd., Tianjin, China) [35]. Briefly, threads were inserted into the lateral canthus of the lower eyelid for $1 \mathrm{~min}$. The length of the red portion of the threads was measured, and the tear volume was expressed in millimeters ( $\mathrm{mm})$.

\subsection{Hematoxylin and Eosin (HEE) Staining}

Fixed eyeballs and lacrimal glands were embedded in paraffin and cut into $5 \mu \mathrm{m}$ sections using a microtome (Leica RM2245, Leica Biosystems, Heidelberg, Germany). The sections were deparaffinized, hydrated, and stained with hematoxylin and eosin (YD Diagnostics Co., Yongin, Korea) The stained slides were observed using the EVOS FL Auto 2 imaging system (Thermo Fisher Scientific, Waltham, MA, USA).

\subsection{Periodic Acid-Schiff (PAS) Staining}

Paraffin-embedded sections of the entire globe were cut into $5 \mu \mathrm{m}$ thickness, and stained using a PAS kit (Sigma-Aldrich Chemical Co., St. Louis, MO, USA) according to the manufacturer's protocol. Images of violet PAS-positive goblet cells were acquired using a microscope (Carl Zeiss, Oberkochen, Germany) at the Core Facility Center for Tissue Regeneration (Dong-eui University, Busan, Korea).

\subsection{Immunohistochemistry}

Sections $5 \mu \mathrm{m}$ thick of the lacrimal gland were deparaffinized, hydrated, processed in antigen retrieval solution (Abcam Inc., Cambridge, UK), and exposed to $3 \% \mathrm{H}_{2} \mathrm{O}_{2}$ solution (Sigma-Aldrich Chemical Co., St. Louis, MO, USA) for $30 \mathrm{~min}$. For immunohistochemical analysis, the slides were incubated with primary antibodies against cluster of differentiation 4 (CD4; Novus Biologicals, Littleton, CO, USA), interleukin-17 (IL-17; Abcam Inc., Cambridge, UK), and tumor necrosis factor alpha (TNF- $\alpha$; Abcam Inc., Cambridge, UK) for $1 \mathrm{~h}$. Subsequently, the sections were incubated with secondary antibodies (DAKO Corp, Glostrup, Denmark) for $40 \mathrm{~min}$, followed by probing with diaminobenzidine chromogen, 
and counterstained with Mayer's hematoxylin (YD Diagnostics Co., Yongin, Korea). The stained slides were photographed using an imaging system (Thermo Fisher Scientific). The quantitative analysis of histological staining for CD4, IL-17, and TNF- $\alpha$ was performed using the "threshold tool" of Image ${ }^{\circledR}$ (National Institutes of Health, Bethesda, MD, USA).

\subsection{Statistical Analysis}

Data are presented as the mean \pm standard deviation. One-way analysis of variance (ANOVA) and post hoc analyses were performed for comparisons between groups using GraphPad Prism 5.03 (GraphPad Software Inc., La Jolla, CA, USA). Statistical significance was set at $p<0.05$.

\section{Results}

\subsection{Effect of CFW on the Physiological Changes in PM 2.5-Exposed Sprague-Dawley (SD) Rats}

Body weight was measured in all groups at 0 and 14 days after topical exposure to $\mathrm{PM}_{2.5}$, with or without treatment. As shown in Table 1, no significant differences were observed in body weight gain and organ weight between the normal group and $\mathrm{PM}_{2.5}$-exposed groups.

Table 1. Effect of oral administration of CFW on the changes of the body weight and organ weight in PM 2.5 -exposed SD rats.

\begin{tabular}{lcccccc}
\hline \multirow{2}{*}{ Organ Weight (g) } & \multicolumn{5}{c}{ Group } \\
\cline { 2 - 7 } & Control & DED & CFW 200 & CFW 400 & Lutein & CsA \\
\hline BW gain & $31.92 \pm 9.35$ & $28.11 \pm 9.03$ & $31.13 \pm 6.94$ & $30.05 \pm 8.07$ & $30.48 \pm 6.77$ & $34.03 \pm 10.04$ \\
Thymus & $0.40 \pm 0.08$ & $0.39 \pm 0.07$ & $0.41 \pm 0.06$ & $0.42 \pm 0.10$ & $0.36 \pm 0.04$ & $0.38 \pm 0.09$ \\
Heart & $0.69 \pm 0.04$ & $0.68 \pm 0.03$ & $0.67 \pm 0.04$ & $0.65 \pm 0.06$ & $0.66 \pm 0.02$ & $0.67 \pm 0.06$ \\
Lung & $1.08 \pm 0.09$ & $1.02 \pm 0.07$ & $1.01 \pm 0.06$ & $0.98 \pm 0.08$ & $0.99 \pm 0.06$ & $1.01 \pm 0.07$ \\
Liver & $6.43 \pm 0.47$ & $6.47 \pm 0.59$ & $6.33 \pm 0.68$ & $6.28 \pm 0.59$ & $6.42 \pm 0.88$ & $6.44 \pm 0.67$ \\
Kidney & $1.52 \pm 0.18$ & $1.47 \pm 0.11$ & $1.49 \pm 0.09$ & $1.51 \pm 0.14$ & $1.45 \pm 0.06$ & $1.49 \pm 0.12$ \\
Spleen & $0.53 \pm 0.04$ & $0.52 \pm 0.07$ & $0.52 \pm 0.07$ & $0.53 \pm 0.05$ & $0.51 \pm 0.08$ & $0.54 \pm 0.04$ \\
Uterus and Ovary & $0.51 \pm 0.10$ & $0.48 \pm 0.08$ & $0.49 \pm 0.11$ & $0.52 \pm 0.10$ & $0.59 \pm 0.18$ & $0.58 \pm 0.14$ \\
\hline
\end{tabular}

The data are expressed as mean \pm standard deviation $(n=5)$. Control, untreated group; $\mathrm{DED}, \mathrm{PM}_{2.5}$ with normal saline-treated group; CFW 200, $\mathrm{PM}_{2.5}$ with $200 \mathrm{mg} / \mathrm{kg}$ of water extracts of Corni Fructus-treated group; CFW 400, $\mathrm{PM}_{2.5}$ with $400 \mathrm{mg} / \mathrm{kg}$ of water extracts of Corni Fructus-treated group; Lutein, $\mathrm{PM}_{2.5}$ with lutein-treated group; and CsA, $\mathrm{PM}_{2.5}$ with cyclosporine A-treated group. CsA, cyclosporin A.

\subsection{Effect of CFW on the Changes of Hematological, Biochemical, and Lipid Profiles in PM ${ }_{2.5}$ Exposed SD Rats}

The hematological analysis results showed no differences among the groups (Table 2). In addition, no biochemical abnormalities were observed among the groups. However, the levels of total cholesterol (TC) were markedly increased to $74.47 \mathrm{mg} / \mathrm{dL}$ following topical exposure to $\mathrm{PM}_{2.5}$, and the levels significantly decreased to control levels after topical administration of $400 \mathrm{mg} / \mathrm{kg}$ CFW, which was similar to the levels observed after CsA topical administration. Moreover, low-density lipoprotein cholesterol (LDL-C) levels were also significantly upregulated in the control group, and the levels were downregulated following $200 \mathrm{mg} / \mathrm{kg}$ and $400 \mathrm{mg} / \mathrm{kg}$ CFW administration. However, oral administration of lutein and topical administration of CsA did not improved serum LDL-C levels. Meanwhile, the levels of high-density lipoprotein cholesterol, triglyceride (TG), and free fatty acid were not different among the groups.

\subsection{Effect of CFW on Tear Secretion after Topical Exposure to $P M_{2.5}$ in SD Rats}

We investigated the effect of the oral administration of CFW on the changes in tear production in $\mathrm{PM}_{2.5}$-applied SD rats. On days 0,7 , and 14, the tear volume was measured using phenol red tear threads. At day 0, no significant difference was observed in tear production among all groups (Figure 1). During the entire study period, the control group showed no significant difference in tear production. At day 7, tear volume was markedly suppressed in the $\mathrm{PM}_{2.5}$-treated DED group $(4.90 \pm 1.14 \mathrm{~mm})$ compared with that in 
the control group $(6.70 \pm 1.05 \mathrm{~mm})$. Although the CFW 200 group $(5.08 \pm 0.66 \mathrm{~mm})$ and the CFW 400 group ( $5.83 \pm 0.75 \mathrm{~mm}$ ) showed no significant difference in tear volume compared with the DED group, the tear production gradually increased in the CFW 400 group. At day 14, $\mathrm{PM}_{2.5}$ treatment greatly suppressed tear secretion to $3.83 \pm 0.61 \mathrm{~mm}$, but oral supplements of $200 \mathrm{mg} / \mathrm{kg}$ CFW and $400 \mathrm{mg} / \mathrm{kg}$ CFW significantly increased tear production to $5.10 \pm 0.86 \mathrm{~mm}$ and $5.65 \pm 0.71 \mathrm{~mm}$, respectively. Meanwhile, tear production in the lutein group and CsA group was also markedly enhanced compared to that in the DED group at day 14 after treatment.

Table 2. Effect of oral administration of CFW on the hematological, biochemical, and lipid profiles in SD rats after topical exposure to $\mathrm{PM}_{2.5}$.

\begin{tabular}{|c|c|c|c|c|c|c|}
\hline & \multicolumn{6}{|c|}{ Group } \\
\hline & Control & DED & CFW 200 & CFW 400 & Lutein & CsA \\
\hline $\operatorname{RBC}\left(10^{6} / \mu \mathrm{L}\right)$ & $8.15 \pm 0.16$ & $8.20 \pm 0.12$ & $8.11 \pm 0.24$ & $8.03 \pm 0.35$ & $8.06 \pm 0.15$ & $7.91 \pm 0.30$ \\
\hline $\operatorname{WBC}\left(10^{3} / \mu \mathrm{L}\right)$ & $5.10 \pm 0.73$ & $4.55 \pm 1.23$ & $4.82 \pm 0.86$ & $4.32 \pm 0.98$ & $4.41 \pm 1.11$ & $4.09 \pm 1.37$ \\
\hline Hematocrit (\%) & $50.04 \pm 1.65$ & $49.58 \pm 1.25$ & $49.96 \pm 2.08$ & $49.42 \pm 2.65$ & $50.56 \pm 1.24$ & $49.62 \pm 2.21$ \\
\hline Hemoglobin(g/dL) & $15.46 \pm 0.21$ & $15.32 \pm 0.17$ & $15.25 \pm 0.82$ & $15.08 \pm 0.95$ & $15.06 \pm 0.69$ & $15.04 \pm 0.51$ \\
\hline MCV (fL) & $61.42 \pm 1.71$ & $60.32 \pm 0.97$ & $60.87 \pm 1.11$ & $61.52 \pm 1.40$ & $61.20 \pm 0.82$ & $61.20 \pm 2.24$ \\
\hline $\mathrm{MCH}(\mathrm{pg})$ & $19.00 \pm 0.32$ & $18.72 \pm 0.34$ & $18.89 \pm 0.63$ & $18.76 \pm 0.62$ & $19.04 \pm 0.45$ & $19.20 \pm 0.71$ \\
\hline $\mathrm{MCHC}(\mathrm{g} / \mathrm{dL})$ & $30.98 \pm 0.57$ & $31.02 \pm 0.27$ & $30.44 \pm 0.61$ & $30.50 \pm 0.44$ & $30.38 \pm 0.73$ & $30.96 \pm 0.47$ \\
\hline Platelet $\left(10^{3} / \mu \mathrm{L}\right)$ & $839.60 \pm 81.15$ & $912.67 \pm 63.07$ & $885.71 \pm 54.83$ & $873.40 \pm 62.96$ & $870.80 \pm 45.92$ & $898.00 \pm 48.46$ \\
\hline AST $(\mathrm{U} / \mathrm{L})$ & $141.26 \pm 24.35$ & $150.88 \pm 20.75$ & $142.18 \pm 19.48$ & $138.04 \pm 23.77$ & $143.28 \pm 15.23$ & $139.30 \pm 21.43$ \\
\hline $\operatorname{ALT}(\mathrm{U} / \mathrm{L})$ & $20.94 \pm 2.49$ & $22.93 \pm 3.68$ & $21.53 \pm 3.05$ & $22.48 \pm 4.14$ & $21.42 \pm 1.57$ & $20.54 \pm 2.55$ \\
\hline $\operatorname{ALP}(\mathrm{U} / \mathrm{L})$ & $428.24 \pm 41.58$ & $428.87 \pm 63.12$ & $431.17 \pm 48.49$ & $421.12 \pm 62.66$ & $439.28 \pm 38.65$ & $428.76 \pm 79.26$ \\
\hline BUN (mg/dL) & $14.19 \pm 0.94$ & $14.40 \pm 1.15$ & $14.38 \pm 1.02$ & $14.89 \pm 0.75$ & $14.22 \pm 1.66$ & $14.43 \pm 1.30$ \\
\hline Creatinine $(\mathrm{mg} / \mathrm{dL})$ & $0.48 \pm 0.03$ & $0.48 \pm 0.04$ & $0.48 \pm 0.02$ & $0.47 \pm 0.03$ & $0.48 \pm 0.02$ & $0.48 \pm 0.03$ \\
\hline $\mathrm{TC}(\mathrm{mg} / \mathrm{dL})$ & $57.98 \pm 3.37$ & $74.47 \pm 5.95 * *$ & $66.18 \pm 3.35$ & $62.20 \pm 3.77^{\#}$ & $65.38 \pm 8.59$ & $60.65 \pm 4.17^{\#}$ \\
\hline $\mathrm{TG}(\mathrm{mg} / \mathrm{dL})$ & $48.44 \pm 5.13$ & $48.00 \pm 7.94$ & $45.77 \pm 5.85$ & $43.64 \pm 6.62$ & $45.26 \pm 8.72$ & $46.58 \pm 8.63$ \\
\hline HDL-C (mg/dL) & $29.50 \pm 3.26$ & $28.35 \pm 3.97$ & $28.97 \pm 3.49$ & $29.18 \pm 3.32$ & $28.56 \pm 3.33$ & $29.32 \pm 4.25$ \\
\hline LDL-C (mg/dL) & $6.08 \pm 0.39$ & $9.68 \pm 1.28^{* * *}$ & $7.78 \pm 0.65^{\#}$ & $7.18 \pm 0.91 \#$ & $8.45 \pm 0.21^{* *}$ & $8.47 \pm 0.90^{* *}$ \\
\hline FFA (uEq/L) & $665.00 \pm 27.81$ & $720.17 \pm 82.88$ & $688.61 \pm 49.04$ & $683.60 \pm 43.76$ & $676.20 \pm 102.10$ & $695.00 \pm 56.31$ \\
\hline
\end{tabular}

The data are expressed as mean \pm standard deviation $(n=5)$. ${ }^{* *} p<0.01$ and ${ }^{* * *} p<0.001$ compared to the control group. ${ }^{\#} p<0.05$ and ${ }^{\#} p<0.01$ compared to $\mathrm{PM}_{2.5}$-induced DED group. RBC, red blood cell; WBC, white blood cell; MCV, mean corpuscular volume; $\mathrm{MCH}$, mean corpuscular hemoglobin; MCHC, MCH concentration; AST, aspartate aminotransferase; ALT, alanine aminotransferase; ALP, alkaline phosphatase; BUN, blood urea nitrogen; TC, total cholesterol; TG, triglyceride; HDL-C, high-density lipoprotein cholesterol; LDL, low-density lipoprotein cholesterol; FFA, free fatty acid.
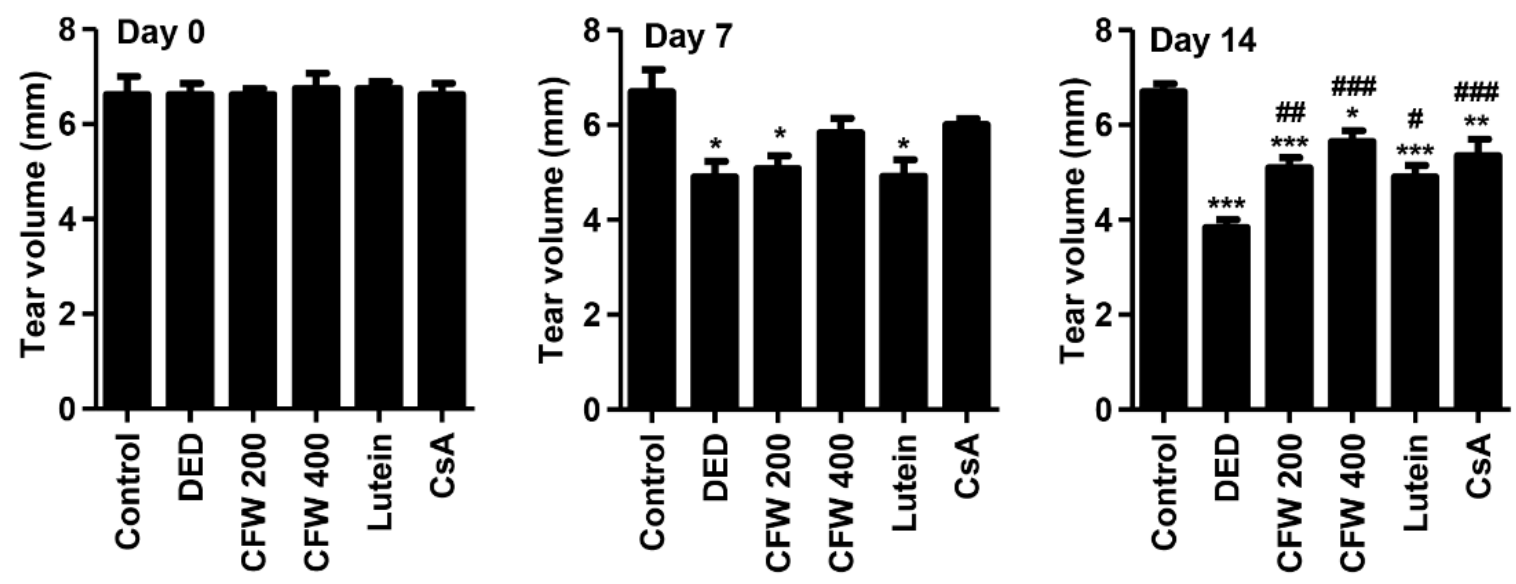

Figure 1. Effect of oral supplements of CFW on tear secretion after topical exposure to $\mathrm{PM}_{2.5}$ in SD rats. On days 0 , 7, and 14 , tear volume was determined using phenol red tear threads and the length of color-changed thread was measured. The data are expressed as the means \pm standard deviation $(n=5) .{ }^{*} p<0.05,{ }^{* *} p<0.01$, and ${ }^{* * *} p<0.001$ compared to the control group. \# $p<0.05$, \#\# $p<0.01$, and \#\#\# $p<0.001$ compared to the $\mathrm{PM}_{2.5}$-induced $D E D$ group. 


\subsection{Effect of CFW on Detachment of Corneal Epithelium in PM 2.5 -Induced DED Rat Model}

To investigate whether topical application of $\mathrm{PM}_{2.5}$ changes the corneal epithelium and the effect of $\mathrm{CFW}$ on $\mathrm{PM}_{2.5}$-mediated epithelium alteration, we performed $\mathrm{H} \& \mathrm{E}$ staining. Figure 2A shows that the detachment and swelling of corneal epithelium were more frequently observed in the DED group; however, CFW 200, CFW 400, lutein, and CsA treatments were markedly protect against PM2.5-induced the alteration. Figure 2B shows that the quantitative values of the detached epithelium are indicated as number per $100 \mu \mathrm{m}^{2}$. Topical exposure to $\mathrm{PM}_{2.5}$ markedly enhanced the detachment of corneal epithelium to $4.13 \pm 0.63 / 100 \mu^{2}$. However, the population of detachment epithelium was markedly decreased to $2.63 \pm 0.48 / 100 \mu \mathrm{m}^{2}$ in the CFW 200 group. Additionally, the detachment of corneal epithelium in the CFW 400 group was greatly suppressed to $1.38 \pm 0.47 / 100 \mu \mathrm{m}^{2}$ compared with that in the DED group. Meanwhile, the efficacy of administration of lutein and CsA on the corneal epithelium detachment was similar, and the levels were suppressed. This result indicated that oral administration of CFW had a protective effect on the detachment of corneal epithelium by topical exposure to $\mathrm{PM}_{2.5}$, and its efficacy was superior to that of lutein and CsA.

(A)
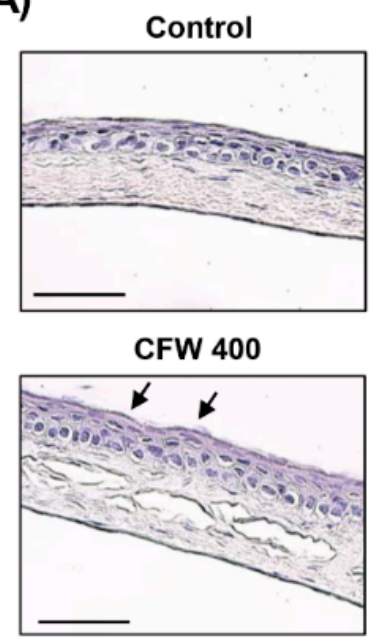

DED

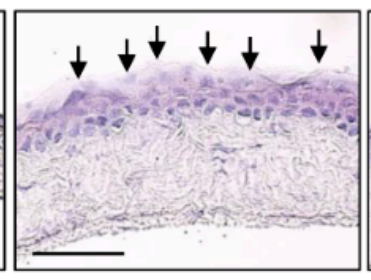

Lutein

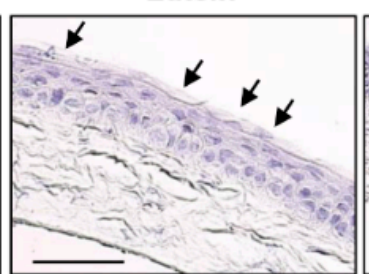

CFW 200

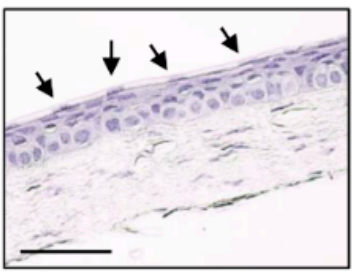

CsA

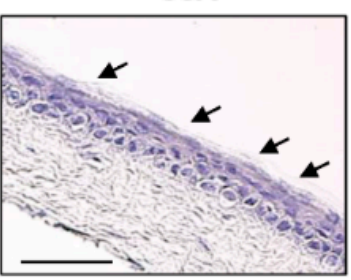

(B)

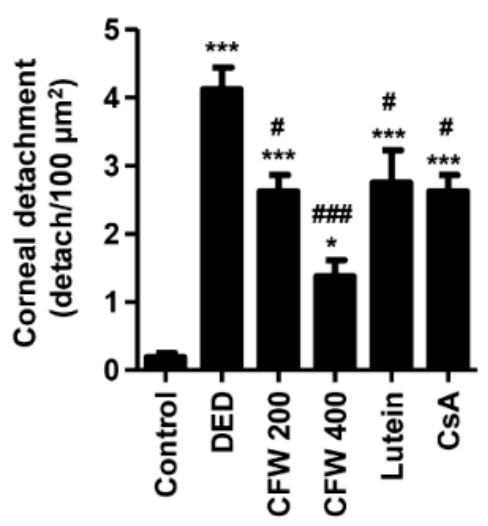

Figure 2. Effect of oral supplements of CFW on the detachment of corneal epithelium in PM 2.5 -induced DED rats. (A) Representative images of H\&E-stained images of corneal sections $(n=4)$. Black arrows indicate the detached and swollen epithelium. Scale bar, $50 \mu \mathrm{m}$. (B) The numbers of the detached corneal epithelium of $100 \mu \mathrm{m}^{2}$ in five different sections were counted. The data are expressed as the means \pm standard deviation $(n=10) .{ }^{*} p<0.05$ and ${ }^{* * *} p<0.001$ compared to the control group. \# $p<0.05$ and \#\#\# $p<0.001$ compared to the $\mathrm{PM}_{2.5}$-induced DED group.

\subsection{Effect of CFW on Conjunctival Goblet Cell Population in PM2.5-Induced DED Rat Model}

To evaluate the population of goblet cells that secrete gel-forming mucins in the conjunctiva, we performed PAS staining. In control rats, a large number of violet PAS-positive goblet cells were observed in the conjunctival tissue (Figure 3A). However, topical exposure to $\mathrm{PM}_{2.5}$ greatly suppressed the frequency of PAS-stained goblet cells, but this was markedly enhanced following CFW 400 administration. Figure 3B shows the quantitative values of the conjunctival goblet cell population, and these are expressed as number per $100 \mu \mathrm{m}^{2}$. The number of conjunctival goblet cells greatly reduced from $4.00 \pm 0.82 / 100 \mu \mathrm{m}^{2}$ to $0.26 \pm 0.55 / 100 \mu \mathrm{m}^{2}$ following exposure to $\mathrm{PM}_{2.5}$. Nevertheless, $\mathrm{PM}_{2.5}$-mediated conjunctival goblet cell loss was substantially recovered by oral administration of CFW in a dose-dependent manner. Furthermore, the density of conjunctival goblet cells in the CFW 400 group was higher than that in the CsA group. Meanwhile, oral administration of lutein did not improve conjunctival goblet cells loss. This result suggested that conjunctival goblet cell loss, a DED-mediated event, was markedly induced following exposure to $\mathrm{PM}_{2.5}$, and this alteration was significantly prevented by oral administration of CFW. 
(A)

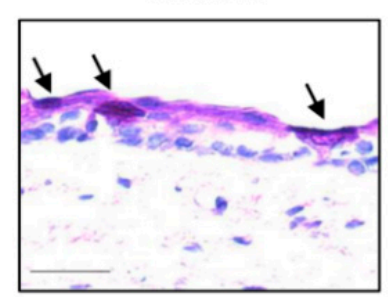

CFW 400

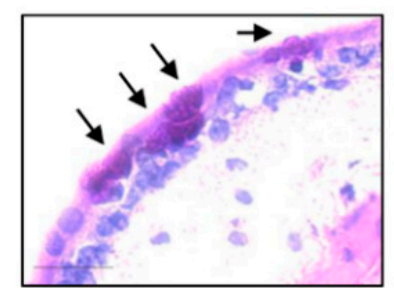

DED

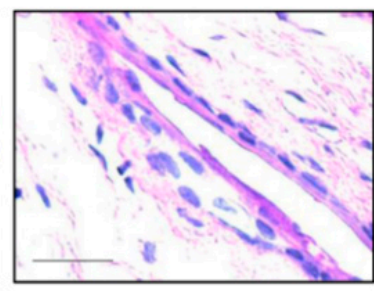

Lutein

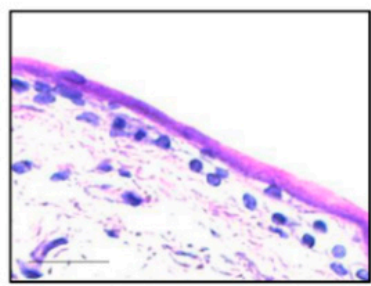

CFW 200

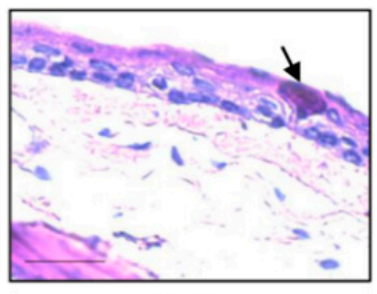

CsA

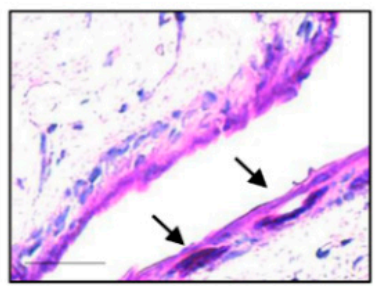

(B)

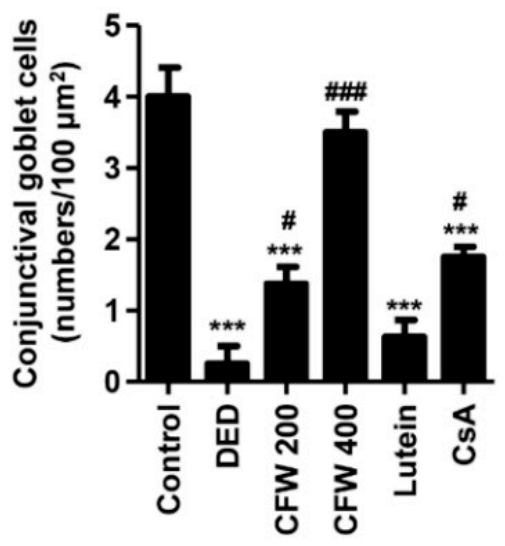

Figure 3. Effect of oral supplements of CFW on conjunctival goblet cell population in $\mathrm{PM}_{2.5}$-induced DED rats. (A) Representative images of PAS-stained images of conjunctival sections $(n=4)$. Black arrows indicate the PAS-stained goblet cells, which appeared a strong violet color. Scale bar, $25 \mu \mathrm{m}$. (B) The numbers of goblet cells of $100 \mu \mathrm{m}^{2}$ in five different sections were counted. The data are expressed as the means \pm standard deviation $(n=10)$. ${ }^{* *} p<0.001$ compared to control group. \# $p<0.05$ and \#\#\# $p<0.001$ compared to the $\mathrm{PM}_{2.5}$-induced DED group.

\subsection{Effect of CFW on Inflammation of Lacrimal Gland in PM 2.5 -Induced DED Rats}

We assessed the effect of CFW on the pathological changes in the lacrimal gland in rats with DED following exposure to $\mathrm{PM}_{2.5}$. Figure $4 \mathrm{~A}$ shows normal secretory gland histology, including tight acini and ducts in control rats. However, exposure to $\mathrm{PM}_{2.5}$ led to inflammatory cell infiltration, sizable interstitial edema with abnormal acini, and the formation of neo-vessels around lobules. In contrast, oral administration of CFW prevented $\mathrm{PM}_{2.5}$-mediated histopathological changes in the lacrimal gland, in a dose-dependent manner. Meanwhile, lutein administration also inhibited infiltration of inflammatory cells and edema with abnormal acini, but neo-vessels around lobules were still slightly present. To further investigate whether $\mathrm{CD} 4^{+} \mathrm{T}$ cell immune responses are involved in $\mathrm{PM}_{2.5}$-mediated histopathological alteration of the lacrimal gland, we performed immunohistochemical staining for specific antibodies, such as CD4, IL-17, and TNF- $\alpha$. The top panels of Figure 4B show that the predominant immune cell subset in the lacrimal glands of $\mathrm{PM}_{2.5}$-exposed rats consisted of $\mathrm{CD} 4^{+} \mathrm{T}$ cells. However, the overexpression of $\mathrm{CD} 4^{+} \mathrm{T}$ cells by $\mathrm{PM}_{2.5}$ was significantly down-regulated to control levels by oral administration of CFW 400 and cyclosporine (Figure 4B,C). In addition, the expression of IL-17 and TNF- $\alpha$ in the lesions of the lacrimal gland was significantly increased to 2.10- and 2.36-fold that of control by $\mathrm{PM}_{2.5}$ topical exposure. However, the upregulated expression was substantially attenuated following CFW 400 and cyclosporine treatment, and was similar to control levels following treatment. However, treatment was less effective on the expression of CD4, IL-17, and TNF- $\alpha$ in lutein group. These results suggest that $\mathrm{PM}_{2.5}$ exposure leads to pathological changes in the lacrimal gland, including inflammation, neovascularization, and abnormal acini, due to $\mathrm{CD}^{+} \mathrm{T}$ cell immune responses. Nevertheless, oral administration of CFW markedly prevented these alterations of the lacrimal gland by $\mathrm{PM}_{2.5}$, and the efficacy of spermidine was similar to that of cyclosporine treatment. 
(A)

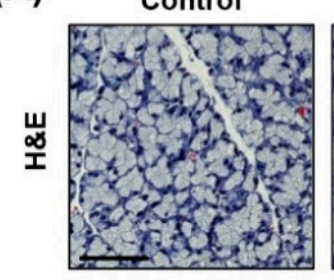

(B)
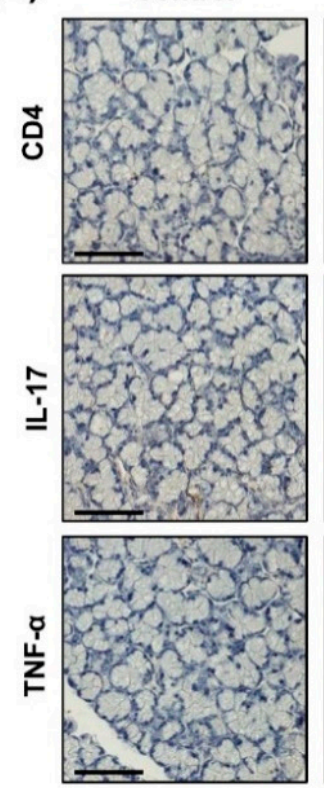

DED

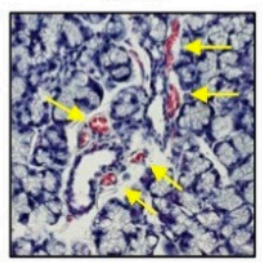

DED
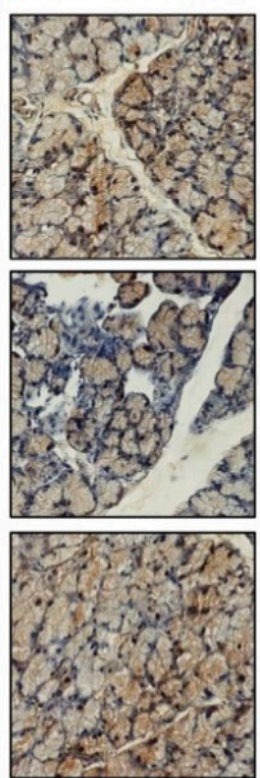

CFW 200

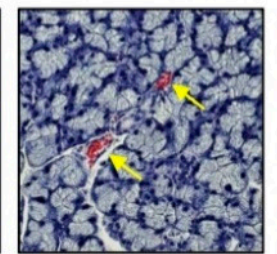

CFW 200
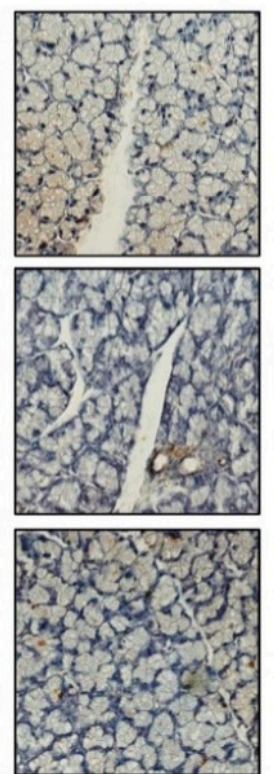

CFW 400

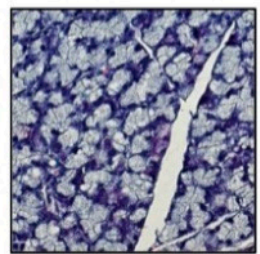

CFW 400
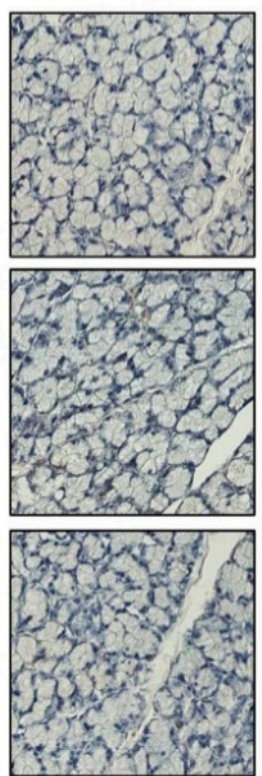

Lutein

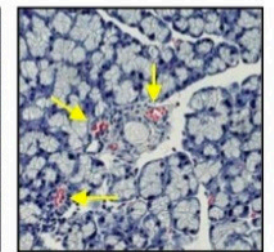

Lutein
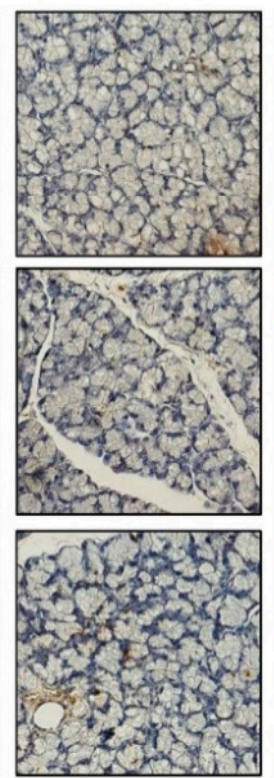

CsA

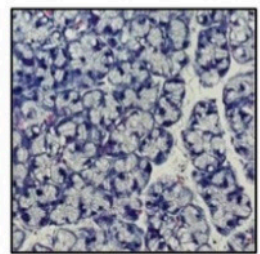

CsA
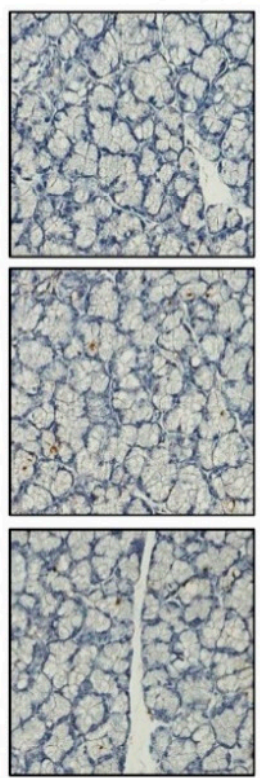

(C)
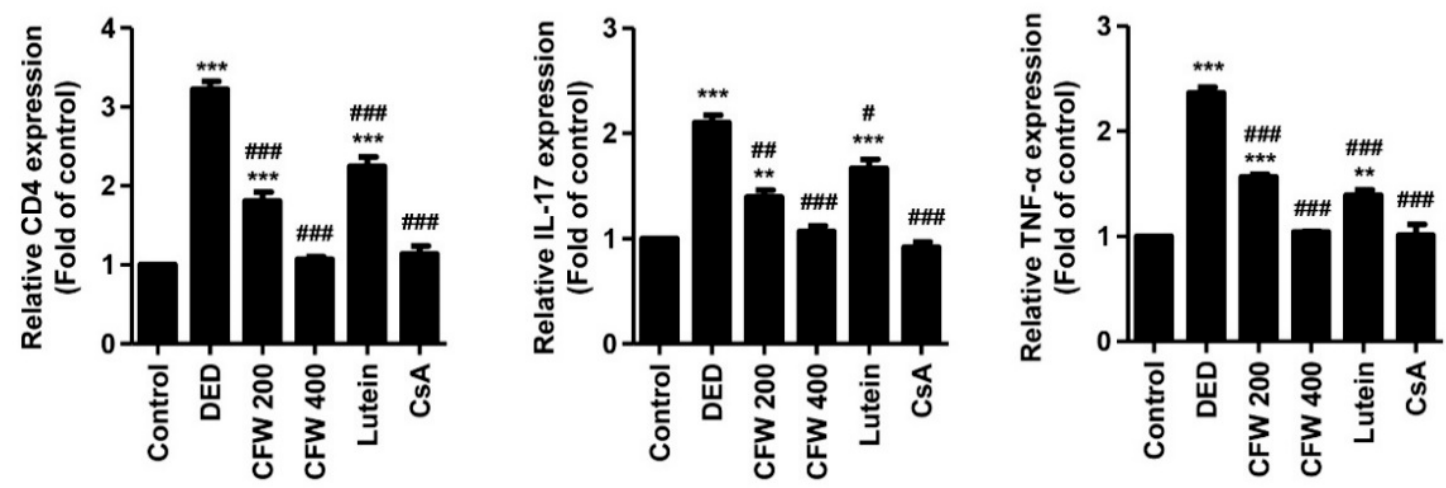

Figure 4. Effect of oral administration of CFW on inflammation of the lacrimal gland in $\mathrm{PM}_{2.5}$-induced DED rats. (A) Representative images of H\&E staining in the lacrimal gland $(n=6)$. Yellow arrows indicate neo-vessels. Scale bar, $50 \mu \mathrm{m}$. (B) Representative images of immunohistochemical staining for CD4, IL-17, and TNF- $\alpha$ in lacrimal gland sections $(n=5)$. Scale bar, $50 \mu \mathrm{m}$. The brown-stained precipitates indicate the presence of the target antigen. (C) The stained area of the photograph was quantitative analyzed using Image ${ }^{\circledR}$ and calculated in terms of the fold of the control. ${ }^{* *} p<0.01$ and ${ }^{* * *} p<0.001$ compared to the control group. The data are expressed as the means \pm standard deviation $(n=3)$. \# $p<0.05, \# \# p<0.01$ and \#\#\# $p<0.001$ compared to the $\mathrm{PM}_{2.5}$-induced DED group.

\subsection{Effect of CFW on Histological Changes of the Retina after Topical Exposure to $P M_{2.5}$ in SD Rats}

Next, we investigated the harmful effects on the retina following topical exposure to $\mathrm{PM}_{2.5}$, and the efficacy of CFW on $\mathrm{PM}_{2.5}$-mediated retinal alteration. As a result of H\&E staining in the retinal section, the thickness of the nerve fiber layer (NFL), ganglion cell layer (GCL), and inner plexiform layer (IPL) markedly decreased by exposure to 
$\mathrm{PM}_{2.5}$, but this was markedly prevented by CFW 400, lutein, and CsA administration (Figure 5A,B). Meanwhile, the thickness of the inner nuclear layer (INL) and outer nuclear layer (ONL) did not differ among the groups. In addition, the population of ganglion cells in GCL was markedly decreased by exposure to topical $\mathrm{PM}_{2.5}$ (Figure 5A). However, the population of ganglion cells was greatly increased after CFW treatment. Figure 5C shows that the number of ganglion cells was significantly decreased in the retina of the DED group $\left(7.42 \pm 1.08 / 100 \mu \mathrm{m}^{2}\right)$ compared with that in the retina of the control group $\left(16.50 \pm 1.98 / 100 \mu \mathrm{m}^{2}\right)$. In contrast, oral administration of $200 \mathrm{mg} / \mathrm{kg}$ and $400 \mathrm{mg} / \mathrm{kg}$ CFW significantly enhanced the ganglion cell population to $11.71 \pm 1.80 / 100 \mu \mathrm{m}^{2}$ and $15.55 \pm 1.93 / 100 \mu \mathrm{m}^{2}$, respectively. The efficacy of CFW 400 on the improvement of ganglion cells was superior to that of cyclosporine, and similar to that of the lutein treatment.

(A)

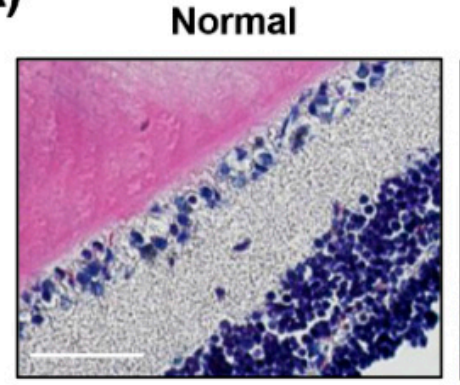

CFW 400

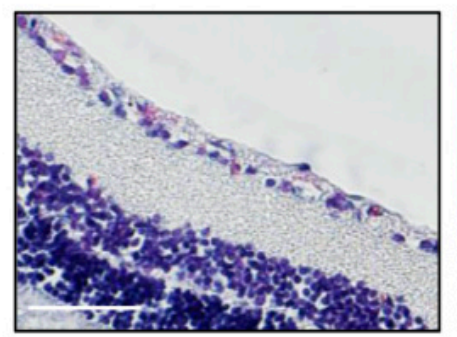

(B)

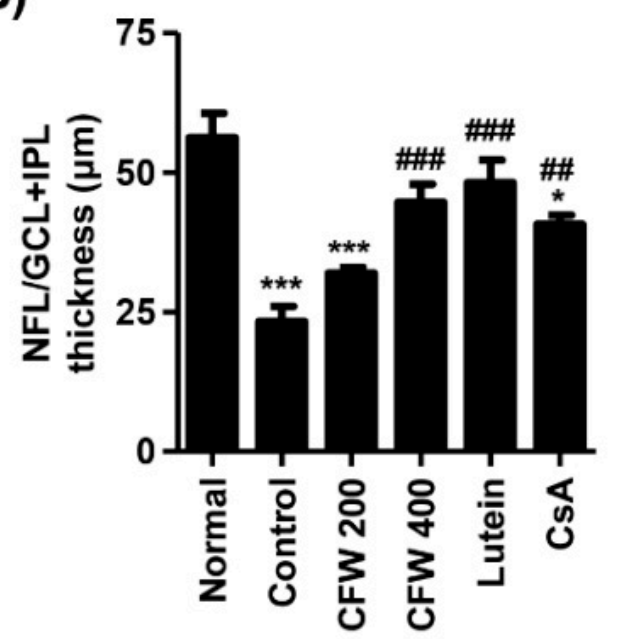

Control

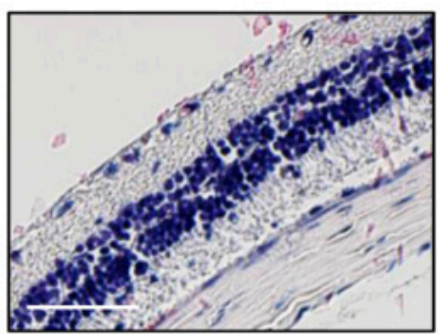

Lutein

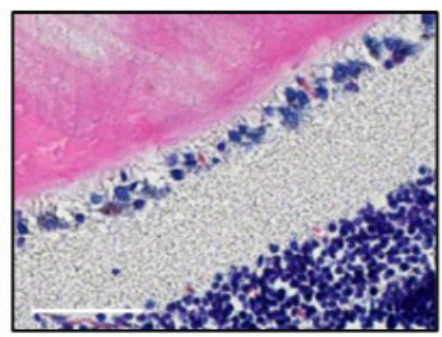

CFW 200

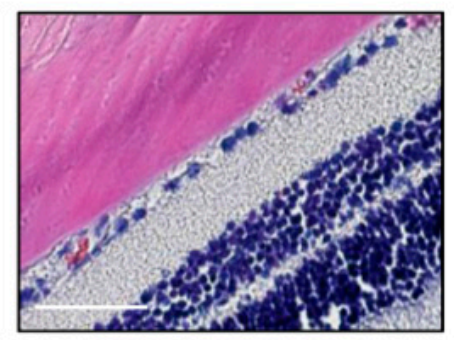

CsA

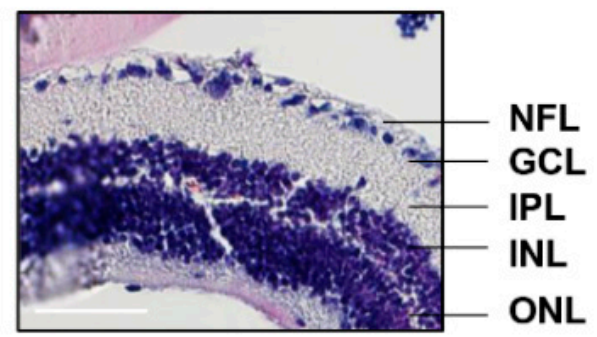

(C)

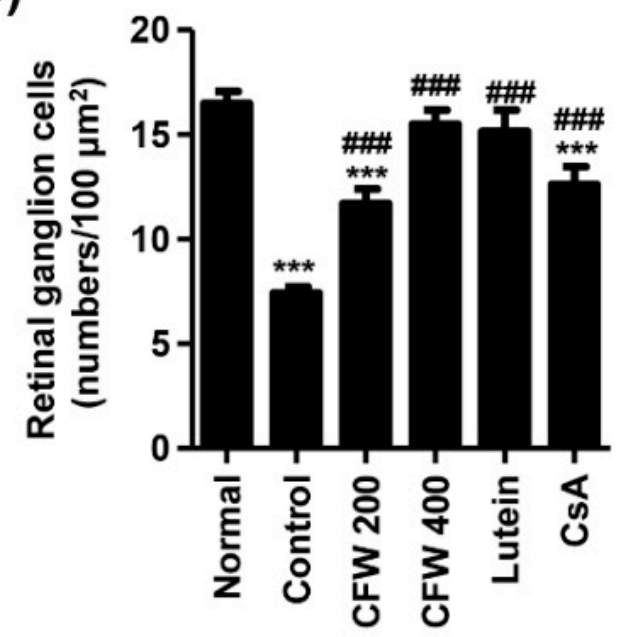

Figure 5. Effect of oral administration of CFW on retinal ganglion cell loss after topical exposure to PM 2.5 in $S D$ rats. (A) Representative images of cross-sectioned retina with H\&E staining $(n=5)$. Nerve fiber layer (NFL), ganglion cell layer (GCL), inner plexiform layer (IPL), inner nuclear layer (INL), and outer nuclear layer (ONL) are indicated. Scale bar, $50 \mu \mathrm{m}$. (B) Thickness of NFL/GCL + IPL layers. (C) The numbers of cells in GCL of $100 \mu \mathrm{m}^{2}$ in five different sections were counted. $(\mathbf{B}, \mathbf{C})$ The data are expressed as the means \pm standard deviation $(n=10) .{ }^{*} p<0.05$ and ${ }^{* * *} p<0.001$ compared to the normal group. \#\# $p<0.01$ and \#\#\# $p<0.001$ compared to the control group. 


\section{Discussion}

In this study, we investigated the effect of oral administration of CFW on the changes of the eyes, as well as on the hematology and biochemistry in a DED model induced by topical exposure to $\mathrm{PM}_{2.5}$. Interestingly, topical exposure to $\mathrm{PM}_{2.5}$ led to partial abnormality of the serum lipid profile, including TC and LDL-C. However, our findings showed that CFW contributes to the normalization of TC and LDL-C levels. Increasing epidemiological studies have recently shown that $\mathrm{PM}_{2.5}$ may have a hazardous influence on the metabolic system, including an increased risk of dyslipidemia [36,37]. One cohort study demonstrated that exposure to $\mathrm{PM}_{2.5}$ is associated with worsening LDL-C levels [36]. In this cohort study, researchers obtained atmospheric monitoring data for the daily mean concentration of hourly measured $\mathrm{PM}_{2.5}$ from the Ministry of Environment of Korea, and multiple regression analyses were conducted to assess the associations between exposure to $\mathrm{PM}_{2.5}$ and changes in lipid profiles at two-year intervals. Another cohort study investigated individual daily exposure to fine PM that was estimated by as spatiotemporal model, and analyzed the correlation between daily exposure levels of fine PM and blood lipid [37]. They suggested that high levels of fine PM exposure were closely correlated with increasing TC and LDL-C levels. Even though these few studies reported that exposure to ambient $\mathrm{PM}_{2.5}$ may have a negative effect on lipid profiles, such as TC and LDL-C, no studies have investigated the influence of topical exposure to $\mathrm{PM}_{2.5}$ on serum lipid profiles. In this context, our findings were very meaningful in that CFW treatment contributed to decrease serum TC and LDL-C levels that were markedly enhanced by topical exposure to $\mathrm{PM}_{2.5}$. Actually, several studies demonstrated that $\mathrm{CF}$ and its bioactive components improved dyslipidemia [38-41]. Park et al. [38] suggested that CF decreased serum TC levels with a suppress in esterified cholesterol in hypercholesterolemic rat. In addition, Zhang et al. [39] demonstrated that polysaccharide isolated from $\mathrm{CF}$ attenuated the cholesterol accumulation in oxidized LDL-stimulated macrophages and suppressed LDL-C, TC, and TG levels in high-fat-diet-fed mice. Furthermore, it has been reported that 7-O-galloyl-D-sedoheptulose, isolated from CF, improved the levels of lipid profile in type 2 diabetic mice [40]. Another study demonstrated that oral administration of iridoid glycoside from CF regulated lipid metabolism in $\mathrm{db} / \mathrm{db}$ mice [41].

The ocular surface is composed of the corneal and conjunctival epithelium, corneoscleral limbus, nerves, and tear film [42]. The ocular surface serves as a barrier to chemicals, microbes, and other airborne matter and provides anatomic, physiologic, and immunologic protective functions [42,43]. Accumulated epidemiological and biochemical studies demonstrate that exposure to $\mathrm{PM}_{2.5}$ may contribute to DED, which is a multifactorial ocular surface disease that involves tear film instability, hyperosmolarity, inflammation, and damage to the ocular surface $[6,8,9,11,12]$. The tear film is composed of three distinct layers, a mucin layer, an aqueous layer, and a lipid layer, and performs many physiological functions [44]. Compromise of the tear film triggers tear film destabilization, promotes exposure of the corneal epithelium to air, and potentially contributes to dry eye symptoms [45]. A mucin layer composed of mucins produced by conjunctival epithelial cells provides an easily wettable ocular surface and assists in tear re-spreading after blinking [46,47]. The conjunctival epithelium houses mucin-producing goblet cells [48]. Recently, several animal studies have demonstrated that topical administration of $\mathrm{PM}_{2.5}$ presented dry eye phenotypes, accompanied by a decreased tear production, damaged corneal epithelium, reduced conjunctival goblet cells, and an abnormal corneal structure [5,12,13,35]. In this context, the clinical characteristic of DED can be diagnosed the tear break up time (TBUT), the tear secretion test and goblet cell counting [5]. In this study, we also reproduced a DED murine model induced by topical instillation of $\mathrm{PM}_{2.5}$, which was accompanied by decreased tear secretion, induced detachment of the corneal epithelium, and loss of conjunctival goblet cells. However, oral administration of CFW significantly protected tear reduction, corneal epithelial detachment, and conjunctival goblet cell loss following $\mathrm{PM}_{2.5}$ exposure. Recently, a newly discovered DED subtype is the short TBUT that is related with ocular neuropathic pain and eye strain [49], The TBUT analysis was developed to 
judge the abnormalities of the tear film [50]. Actually, several previous studies reported that $\mathrm{PM}_{2.5}$ markedly decreased TBUT in DED murine models $[5,12,13,35]$. Although our current result suggested that CFW treatment involved in increment of tear production, the further studies are need to verify the efficacy of CFW on TBUT in $\mathrm{PM}_{2.5}$-exposed DED model. Nevertheless, our present finding showed that recovery of conjunctival goblet cells by oral administration of CFW may contribute to the stabilization of the mucin layer and lead to tear film stability. Therefore, this finding supported that oral application of CFW increased tear production and induced tear film stability through reinforcement of the mucin layer and this was ultimately caused by ocular surface stability.

The major pathogenesis of DED is an inflammation, including infiltrated immune cells in the conjunctiva and lacrimal glands, increased density of dendritic cells in the cornea, and increased secretion levels of tear cytokines [51,52]. Inflammation of the ocular surface in DED is sustained by the ongoing activation and infiltration of pathogenic immune cells, primarily of $\mathrm{CD}^{+} \mathrm{T}$ cells [53]. The main proliferating subset of dry eye $\mathrm{T}$ cell effectors in the presence of $\mathrm{T}$ regulatory cells is IL-17-secreting $\mathrm{CD}^{+} \mathrm{T}$ cells [54]. IL-17 induces the secretion of pro-inflammatory cytokines such as IL-1, IL-6, and TNF- $\alpha$, and these cytokines are upregulated in DED [55]. In this regard, one study reported that the topical application of $\mathrm{PM}_{2.5}$ elevated dendritic cell maturation and the expression of TNF- $\alpha$, IL-1 $\beta$, and IL-6 in a murine model [56]. Another study also reported that the expression of TNF- $\alpha$ and IL- 6 was increased in the $\mathrm{PM}_{2.5}$-induced DED rat [57]. Although the role of CD4 ${ }^{+} \mathrm{T}$ cell-mediated immune responses in DED is well-established, there are no studies on the relationship between $\mathrm{CD}^{+} \mathrm{T}$ cell-mediated immune responses in $\mathrm{PM}_{2.5}$-induced DED. Just one study verified that $\mathrm{PM}_{2.5}$-stimulated $\mathrm{CD} 4^{+} \mathrm{T}$ cells potently increased the mRNA and protein levels of pro-inflammatory cytokines and induced the death of human bronchial epithelial cells [58]. Herein, we found that topical exposure to $\mathrm{PM}_{2.5}$ was caused by the pathological changes in the lacrimal gland, including inflammation, neovascularization, and abnormal acini. Additionally, $\mathrm{PM}_{2.5}$ increased the expression of $\mathrm{CD} 4^{+} \mathrm{T}$ cells, IL-17, and TNF- $\alpha$ in the lacrimal gland. However, oral administration of $400 \mathrm{mg} / \mathrm{kg}$ CFW markedly protected these $\mathrm{PM}_{2.5}$-mediated inflammatory responses of the lacrimal gland, and the efficacy of CFW was similar to that of cyclosporine treatment and superior to that of lutein. These results indicate that oral supplements of CFW may contribute to the suppression of $\mathrm{CD}^{+} \mathrm{T}$ cell immune responses induced by $\mathrm{PM}_{2.5}$. Furthermore, we considered that the protective effect of CFW on lacrimal gland inflammation in $\mathrm{PM}_{2.5}$-exposed rats was due to its anti-inflammatory potential [22,27].

The blood-retina barrier (BRB) is available for diffusion and permeabilization of $\mathrm{PM}_{2.5}$, and its function in BRB could potentially play a role in $\mathrm{PM}_{2.5}$-mediated retinal pathogenesis $[59,60]$. Several epidemiological studies have suggested that exposure to $\mathrm{PM}_{2.5}$ correlates with retinal damage, including retinal atherosclerosis, retinal edema, and retinal vessel narrowing [59-61]. One study demonstrated that topical exposure to $\mathrm{PM}_{2.5}$ markedly decreased the NFL/GCL and increased the expression of glial fibrillary acidic protein [4]. Furthermore, a correlation between $\mathrm{PM}_{2.5}$ and changes in retinal structure features in subjects exposed to higher levels of $\mathrm{PM}_{2.5}$ was reported [59]. Previously, we suggested that $\mathrm{PM}_{2.5}$ mediates retinal dysfunction through ROS-mediated epithelialmesenchymal transition and necrotic and autophagic cell death in retinal pigment epithelial cells $[62,63]$. Our present findings showed that topical exposure to $\mathrm{PM}_{2.5}$ led to the loss of retinal ganglion cells and the decrease of the NFL/GCL + IPL thickness; however, oral administration of CFW contributed to the normalization of retinal ganglion cell density and retinal constitution.

In the present study, we used two positive controls: CsA and lutein. CsA is a T cell immunomodulatory agent that is used to suppress ocular surface inflammation and improve tear film dynamics [32,33]. To date, the effect of CsA on $\mathrm{PM}_{2.5}$-exposed eyes is yet to be reported. Our results showed that CsA attenuated the DED symptoms, including decreasing tear secretion, epithelium detachment, loss of conjunctival goblet cells, and inflammation of lacrimal gland following topical exposure to $\mathrm{PM}_{2.5}$. In addition, CsA im- 
proved serum TC levels and restored retinal ganglion cell population and NFL/GCL + IPL thickness, which is the first finding for the effect of CsA on the posterior segment of the eye following exposure to $\mathrm{PM}_{2.5}$. However, this efficacy of CsA is less or similar than that of CFW. It is also noteworthy that CsA is an immunosuppressant drug widely used oral medications in organ transplant recipients and patients with autoimmune disorders. Some studies reported that long-term treatment with oral administration of CsA was associated with hyperlipidemia and an increased risk of atherosclerosis, but the mechanisms by which cyclosporin A causes hyperlipidemia are unclear $[64,65]$. However, these previous reports about the side effects of oral CsA administration are contrary with our present finding. The differences between previous study and the present study are the administered period and route. Therefore, we consider that further studies are needed to verify whether improvement of TC levels by CsA eye drops is a temporary situation, and to evaluate the effect of long-term topical application of CsA.

Meanwhile, lutein is one of the xanthophyll carotenoids and has posterior eyeprotective properties through anti-oxidative and anti-inflammatory effects [31]. Numerous clinical studies suggested that lutein supplements reduce neovascular age-related macular degeneration (AMD) risk, improve visual function, and increase macular pigment optical density [66-68]. However, the effect of lutein on $\mathrm{PM}_{2.5}$-exposed eyes, especially ocular surface, is yet to be reported. In the present study, we found that lutein had slightly improved efficacy or no efficacy on the anterior segment of eye in $\mathrm{PM}_{2.5}$-exposed rat, but very superior efficacy on the posterior segment of eye. Oral administration of lutein caused a minor increase in tear secretion and corneal epithelium stabilization, and inhibited inflammation of the lacrimal gland, while it had no effect on the conjunctival goblet cell loss. On the other hand, the lutein supplement markedly increased the retinal ganglion cell population and NFL/GCL + IPL thickness following exposure to $\mathrm{PM}_{2.5}$. Interestingly, the efficacy of CFW on the retina was similar to that of lutein. Overall, in the present study, we found that oral administration of CFW protected against $\mathrm{PM}_{2.5}$-induced DED symptoms, retinal disorder, and dyslipidemia. More importantly, the efficacy of CFW was superior and/or similar to that of cyclosporine A, an anti-inflammatory agent, and lutein, the posterior eye-protective agent.

Numerous reports demonstrated that women are disproportionately affected by DED, are diagnosed at a younger age, and experience more severe symptoms compared with men $[69,70]$. Similar to the human studies, several animal studies suggested female sex is a risk factor for DED [5,71,72]. McClellan et al. [71] reported that female C57BL/ 6 mice developed greater corneal barrier disruption than age-matched male mice did, although other features of DED such as low goblet cell density and LG infiltration were similar in both sexes. Recently, Song et al. [72] used six-week-old female SD rats to assess the effect of natural products on a $\mathrm{PM}_{2.5}$-induced DED model. Yang et al. [5] also used 6-8-week-old female C57BL/ 6 mice to evaluated the harmful effect of $\mathrm{PM}_{2.5}$ on the eye. Based on this knowledge, we demonstrated that CFW prevented $\mathrm{PM}_{2.5}$-indued DED in female SD rats. Although we assessed the effect of $\mathrm{CFW}$ on $\mathrm{PM}_{2.5}$-exposed female SD rats, we consider that further studies are needed to evaluate the influence of topical exposure to $\mathrm{PM}_{2.5}$, and to confirm the efficacy of CFW in males.

\section{Conclusions}

Taken together, our present findings indicated that oral administration of CFW contribute to normalize the levels of serum TC and LDL-C in the topical $\mathrm{PM}_{2.5}$-exposed rat. Furthermore, oral administration of CFW protected tear film destabilization, inflammation of the lacrimal gland, and histological changes in the retinal NFL/GCL and IPL in the $\mathrm{PM}_{2.5}$-induced DED. Therefore, the present findings may provide an experimental basis for the potential application of CFW in preventing air pollution-related dry eye symptoms, retinal disorders, and lipid metabolism disorder. 
Author Contributions: Conceptualization, H.L., C.P., S.H.H. and Y.H.C.; methodology, C.P., S.H.H. and G.-Y.K.; software, Y.H.C.; validation, D.H.K. and H.H.; formal analysis, H.L., M.Y.K. and S.Y.J.; investigation, H.L., M.Y.K., S.Y.J., D.H.K., S.Y.K. and H.H.; resources, S.H.H. and Y.H.C.; data curation, S.Y.K. and G.-Y.K.; writing-original draft preparation, H.L., C.P. and Y.H.C.; writing-review and editing, S.H.H., G.-Y.K. and Y.H.C.; visualization, H.L., S.Y.K. and H.H.; supervision, Y.H.C.; project administration, S.Y.J. and G.-Y.K.; funding acquisition, H.L. and Y.H.C. All authors have read and agreed to the published version of the manuscript.

Funding: This work was funded by the Basic Science Research Program through the National Research Foundation (grant numbers, 2019R1C1C1008623 and 2021R1A2C200954911).

Institutional Review Board Statement: Animal care and all experiments were performed in accordance with the Guide for Animal Experimentation of Dong-eui University with the approval of the Institutional Animal Care and Use Committee (IACUC approval No. R2019-005).

Informed Consent Statement: Not applicable.

Data Availability Statement: The datasets during and/or analyzed during the current study are available from the corresponding author on reasonable request.

Conflicts of Interest: The authors declare that they have no competing interest.

\section{References}

1. Bo, Y.; Chang, L.Y.; Guo, C.; Lin, C.; Lau, A.K.H.; Tam, T.; Lao, X.Q. Reduced ambient PM2.5, better lung function, and decreased risk of chronic obstructive pulmonary disease. Environ. Int. 2021, 156, 106706. [CrossRef] [PubMed]

2. Santibáñez-Andrade, M.; Chirino, Y.I.; González-Ramírez, I.; Sánchez-Pérez, Y.; García-Cuellar, C.M. Deciphering the code between air pollution and disease: The effect of particulate matter on cancer hallmarks. Int. J. Mol. Sci. 2019, 21, 136. [CrossRef] [PubMed]

3. Hwang, M.; Han, S.; Seo, J.W.; Jeon, K.J.; Lee, H.S. Traffic-related particulate matter aggravates ocular allergic inflammation by mediating dendritic cell maturation. J. Toxicol. Environ. Health A 2021, 84, 661-673. [CrossRef]

4. Kang, W.S.; Choi, H.; Jang, G.; Lee, K.H.; Kim, E.; Kim, K.J.; Jeong, G.Y.; Kim, J.S.; Na, C.S.; Kim, S. Long-term exposure to urban particulate matter on the ocular surface and the incidence of deleterious changes in the cornea, conjunctiva and retina in rats. Int. J. Mol. Sci. 2020, 21, 4976. [CrossRef]

5. Yang, Q.; Li, K.; Li, D.; Zhang, Y.; Liu, X.; Wu, K. Effects of fine particulate matter on the ocular surface: An in vitro and in vivo study. Biomed. Pharm. 2019, 117, 109177. [CrossRef]

6. Jung, S.J.; Mehta, J.S.; Tong, L. Effects of environment pollution on the ocular surface. Ocul. Surf. 2018, 16, 198-205. [CrossRef]

7. De Paiva, C.S. Effects of aging in dry eye. Int. Ophthalmol. Clin. 2017, 57, 47-64. [CrossRef]

8. Hessen, M.; Akpek, E.K. Dry eye: An inflammatory ocular disease. J. Ophthalmic Vis. Res. 2014, 9, $240-250$.

9. Craig, J.P.; Nichols, K.K.; Akpek, E.K.; Caffery, B.; Dua, H.S.; Joo, C.K.; Liu, Z.; Nelson, J.D.; Nichols, J.J.; Tsubota, K.; et al. TFOS DEWS II definition and classification report. Ocul. Surf. 2017, 15, 276-283. [CrossRef]

10. Fu, Q.; Mo, Z.; Lyu, D.; Zhang, L.; Qin, Z.; Tang, Q.; Yin, H.; Xu, P.; Wu, L.; Lou, X.; et al. Air pollution and outpatient visits for conjunctivitis: A case-crossover study in Hangzhou, China. Environ. Pollut. 2017, 231 Pt 2, 1344-1350. [CrossRef]

11. Mo, Z.; Fu, Q.; Lyu, D.; Zhang, L.; Qin, Z.; Tang, Q.; Yin, H.; Xu, P.; Wu, L.; Wang, X.; et al. Impacts of air pollution on dry eye disease among residents in Hangzhou, China: A case-crossover study. Environ. Pollut. 2019, 246, 183-189. [CrossRef]

12. Tan, G.; Li, J.; Yang, Q.; Wu, A.; Qu, D.Y.; Wang, Y.; Ye, L.; Bao, J.; Shao, Y. Air pollutant particulate matter 2.5 induces dry eye syndrome in mice. Sci. Rep. 2018, 8, 17828. [CrossRef]

13. Yang, Q.C.; Bao, J.; Li, C.; Tan, G.; Wu, A.H.; Ye, L.; Ye, L.H.; Zhou, Q.; Shao, Y. A murine model of dry eye induced by topical administration of erlotinib eye drops. Int. J. Mol. Med. 2018, 41, 1427-1436. [CrossRef]

14. Song, S.J.; Hyun, S.W.; Lee, T.G.; Park, B.; Jo, K.; Kim, C.S. New application for assessment of dry eye syndrome induced by particulate matter exposure. Ecotoxicol. Environ. Saf. 2020, 205, 111125. [CrossRef]

15. Kashiwagi, K.; Iizuka, Y. Effect and underlying mechanisms of airborne particulate matter $2.5\left(\mathrm{PM}_{2.5}\right)$ on cultured human corneal epithelial cells. Sci. Rep. 2020, 10, 19516. [CrossRef]

16. Niu, L.; Li, L.; Xing, C.; Luo, B.; Hu, C.; Song, M.; Niu, J.; Ruan, Y.; Sun, X.; Lei, Y. Airborne particulate matter (PM 2.5$)$ triggers cornea inflammation and pyroptosis via NLRP3 activation. Ecotoxicol. Environ. Saf. 2021, 207, 111306. [CrossRef]

17. Hyun, S.W.; Song, S.J.; Park, B.; Lee, T.G.; Kim, C.S. Toxicological effects of urban particulate matter on corneal and conjunctival epithelial cells. Toxicol. Res. 2020, 36, 311-318. [CrossRef]

18. Dong, Y.; Feng, Z.L.; Chen, H.B.; Wang, F.S.; Lu, J.H. Corni Fructus: A review of chemical constituents and pharmacological activities. Chin. Med. 2018, 13, 34. [CrossRef]

19. Huang, J.; Zhang, Y.; Dong, L.; Gao, Q.; Yin, L.; Quan, H.; Chen, R.; Fu, X.; Lin, D. Ethanopharmacoloy, phytochemistry, and pharmacology of Cornus officinalis Sieb. Et Zucc. J. Ethnopharmacol. 2018, 213, 280-301. [CrossRef] 
20. Chang, J.S.; Chiang, L.C.; Hsu, F.F.; Lin, C.C. Chemoprevention against hepatocellular carcinoma of Cornus officinalis in vitro. Am. J. Chin. Med. 2004, 32, 717-725. [CrossRef]

21. Telang, N.T.; Li, G.; Sepkovic, D.W.; Bradlow, H.L.; Wong, G.Y. Antiproliferative effects of Chinese herb Cornus officinalis in a cell culture model for estrogen receptor-positive clinical breast cancer. Mol. Med. Rep. 2012, 5, 22-28. [PubMed]

22. Kang, D.G.; Moon, M.K.; Lee, A.S.; Kwon, T.O.; Kim, J.S.; Lee, H.S. Cornuside suppresses cytokine-induced proinflammatory and adhesion molecules in the human umbilical vein endothelial cells. Biol. Pharm. Bull. 2007, 30, 1796-1799. [CrossRef]

23. Jiang, W.L.; Chen, X.G.; Zhu, H.B.; Hou, J.; Tian, J.W. Cornuside attenuates apoptosis and ameliorates mitochondrial energy metabolism in rat cortical neurons. Pharmacology 2009, 84, 162-170. [CrossRef] [PubMed]

24. Hwang, K.A.; Hwang, Y.J.; Song, J. Antioxidant activities and oxidative stress inhibitory effects of ethanol extracts from Cornus officinalis on raw 264.7 cells. BMC Complement Altern. Med. 2016, 16, 196. [CrossRef]

25. Hwangbo, H.; Kwon, D.H.; Choi, E.O.; Kim, M.Y.; Ahn, K.I.; Ji, S.Y.; Kim, J.S.; Kim, K.I.; Park, N.; Kim, B.H.; et al. Corni Fructus attenuates testosterone-induced benign prostatic hyperplasia by suppressing $5 \alpha$-reductase and androgen receptor expression in rats. Nutr. Res. Pract. 2018, 12, 378-386. [CrossRef]

26. Fernando, P.D.S.M.; Piao, M.J.; Zhen, A.X.; Ahn, M.J.; Yi, J.M.; Choi, Y.H.; Hyun, J.W. Extract of Cornus officinalis Protects Keratinocytes from Particulate Matter-induced Oxidative Stress. Int. J. Med. Sci. 2020, 17, 63-70. [CrossRef] [PubMed]

27. Park, C.; Cha, H.J.; Lee, H.; Kim, G.Y.; Choi, Y.H. The regulation of the TLR4/NF-kB and Nrf2/HO-1 signaling pathways is involved in the inhibition of lipopolysaccharide-induced inflammation and oxidative reactions by morroniside in RAW 264.7 macrophages. Arch. Biochem. Biophys. 2021, 706, 108926. [CrossRef]

28. Cao, G.; Cai, H.; Cai, B.; Tu, S. Effect of 5-hydroxymethylfurfural derived from processed Cornus officinalis on the prevention of high glucose-induced oxidative stress in human umbilical vein endothelial cells and its mechanism. Food Chem. 2013, 140, 273-279. [CrossRef] [PubMed]

29. Pi, W.X.; Feng, X.P.; Ye, L.H.; Cai, B.C. Combination of morroniside and diosgenin prevents high glucose-induced cardiomyocytes apoptosis. Molecules 2017, 22, 163. [CrossRef]

30. Park, C.; Lee, H.; Kwon, C.Y.; Kim, G.Y.; Jeong, J.W.; Kim, S.O.; Choi, S.H.; Jeong, S.J.; Noh, J.S.; Choi, Y.H. Loganin inhibits lipopolysaccharide-induced inflammation and oxidative response through the activation of the Nrf2/HO-1 signaling pathway in RAW264.7 macrophages. Biol. Pharm. Bull. 2021, 44, 875-883. [CrossRef] [PubMed]

31. Li, L.H.; Lee, J.C.; Leung, H.H.; Lam, W.C.; Fu, Z.; Lo, A.C.Y. Lutein supplementation for eye diseases. Nutrients 2020, $12,1721$. [CrossRef]

32. Matossian, C.; Trattler, W.; Loh, J. Dry eye treatment with topical cyclosporine $0.1 \%$ in chondroitin sulfate ophthalmic emulsion. Clin. Ophthalmol. 2021, 15, 1979-1984. [CrossRef]

33. Lin, X.; Wu, Y.; Tang, L.; Ouyang, W.; Yang, Y.; Liu, Z.; Wu, J.; Zheng, X.; Huang, C.; Zhou, Y.; et al. Comparison of treatment effect and tolerance of the topical application of Mizoribine and Cyclosporine A in a mouse dry eye model. Transl. Vis. Sci. Technol. 2020, 9, 22. [CrossRef]

34. Kang, M.J.; Gong, J.E.; Kim, J.E.; Choi, H.J.; Bae, S.J.; Choi, Y.J.; Lee, S.J.; Seo, M.S.; Kim, K.S.; Jung, Y.S.; et al. Influence of three BALB/c substrain backgrounds on the skin tumor induction efficacy to DMBA and TPA cotreatment. Lab. Anim. Res. 2020, 36, 30. [CrossRef]

35. Lee, T.G.; Hyun, S.W.; Jo, K.; Park, B.; Lee, I.S.; Song, S.J.; Kim, C.S. Achyranthis radix extract improves urban particulate matter-induced dry eye disease. Int. J. Environ. Res. Public Health 2019, 16, 3229. [CrossRef]

36. Shin, W.Y.; Kim, J.H.; Lee, G.; Choi, S.; Kim, S.R.; Hong, Y.C.; Park, S.M. Exposure to ambient fine particulate matter is associated with changes in fasting glucose and lipid profiles: A nationwide cohort study. BMC Public Health 2020, 20, 430. [CrossRef]

37. Mao, S.; Li, S.; Wang, C.; Liu, Y.; Li, N.; Liu, F.; Huang, S.; Liu, S.; Lu, Y.; Mao, Z.; et al. Is long-term PM1 exposure associated with blood lipids and dyslipidemias in a Chinese rural population? Environ. Int. 2020, 138, 105637. [CrossRef] [PubMed]

38. Park, C.H.; Cho, E.J.; Yokozawa, T. Protection against hypercholesterolemia by Corni fructus extract and its related protective mechanism. J. Med. Food 2009, 12, 973-981. [CrossRef] [PubMed]

39. Zhang, X.W.; Sui, Y.; Liu, X.X.; Fu, C.Y.; Qiao, Y.H.; Liu, W.J.; Li, Z.Z.; Li, X.Q.; Cao, W. Structures and anti-atherosclerotic effects of 1,6- $\alpha$-glucans from Fructus Corni. Int. J. Biol. Macromol. 2020, 161, 1346-1357. [CrossRef]

40. Park, C.H.; Tanaka, T.; Yokozawa, T. Evaluation of 7-O-galloyl-D-sedoheptulose, isolated from Corni Fructus, in the adipose tissue of type 2 diabetic $\mathrm{db} / \mathrm{db}$ mice. Fitoterapia 2013, 89, 131-142. [CrossRef]

41. Yamabe, N.; Noh, J.S.; Park, C.H.; Kang, K.S.; Shibahara, N.; Tanaka, T.; Yokozawa, T. Evaluation of loganin, iridoid glycoside from Corni Fructus, on hepatic and renal glucolipotoxicity and inflammation in type 2 diabetic db/db mice. Eur. J. Pharmacol. 2010, 648, 179-187. [CrossRef]

42. Sridhar, M.S. Anatomy of cornea and ocular surface. Indian J. Ophthalmol. 2018, 66, 190-194.

43. Mandell, J.T.; Idarraga, M.; Kumar, N.; Galor, A. Impact of air pollution and weather on dry eye. J. Clin. Med. 2020, 9, 3740. [CrossRef]

44. Davidson, H.J.; Kuonen, V.J. The tear film and ocular mucins. Vet. Ophthalmol. 2004, 7, 71-77. [CrossRef]

45. Zhou, L.; Beuerman, R.W. Tear analysis in ocular surface diseases. Prog. Retin. Eye Res. 2012, 31, 527-550. [CrossRef]

46. Cwiklik, L. Tear film lipid layer: A molecular level view. Biochim. Biophys. Acta 2016, 1858, 2421-2430. [CrossRef]

47. King-Smith, P.E.; Fink, B.A.; Hill, R.M.; Koelling, K.W.; Tiffany, J.M. The thickness of the tear film. Curr. Eye Res. 2004, 29, 357-368. [CrossRef] 
48. Inatomi, T.; Spurr-Michaud, S.; Tisdale, A.S.; Zhan, Q.; Feldman, S.T.; Gipson, I.K. Expression of secretory mucin genes by human conjunctival epithelia. Investig. Ophthalmol. Vis. Sci. 1996, 37, 1684-1692.

49. Kojima, T.; Dogru, M.; Kawashima, M.; Nakamura, S.; Tsubota, K. Advances in the diagnosis and treatment of dry eye. Prog. Retin. Eye Res. 2020, 78, 100842. [CrossRef] [PubMed]

50. Yokoi, N.; Georgiev, G.A.; Kato, H.; Komuro, A.; Sonomura, Y.; Sotozono, C.; Tsubota, K.; Kinoshita, S. Classification of Fluorescein Breakup Patterns: A Novel Method of Differential Diagnosis for Dry Eye. Am. J. Ophthalmol. 2017, 180, 72-85. [CrossRef] [PubMed]

51. Yamaguchi, T. Inflammatory response in dry eye. Investig. Ophthalmol. Vis. Sci. 2018, 59, DES192-DES199. [CrossRef]

52. Belfort, R., Jr.; Mendes, N.F. Identification of T and B lymphocytes in the human conjunctiva and lacrimal gland in ocular diseases. Br. J. Ophthalmol. 1980, 64, 217-219. [CrossRef]

53. Dana, M.R.; Hamrah, P. Role of immunity and inflammation in corneal and ocular surface disease associated with dry eye. Adv. Exp. Med. Biol. 2002, 506 Pt B, 729-738.

54. Korn, T.; Reddy, J.; Gao, W.; Bettelli, E.; Awasthi, A.; Petersen, T.R.; Bäckström, B.T.; Sobel, R.A.; Wucherpfennig, K.W.; Strom, T.B.; et al. Myelin-specific regulatory T cells accumulate in the CNS but fail to control autoimmune inflammation. Nat. Med. 2007, 13, 423-431. [CrossRef]

55. McGeachy, M.J.; Cua, D.J. Th17 cell differentiation: The long and winding road. Immunity 2008, 28, 445-453. [CrossRef]

56. Lee, H.S.; Han, S.; Seo, J.W.; Jeon, K.J. Exposure to traffic-related particulate matter 2.5 triggers Th2-dominant ocular immune response in a murine model. Int. J. Environ. Res. Public Health 2020, 17, 2965. [CrossRef]

57. Hyun, S.W.; Kim, J.; Park, B.; Jo, K.; Lee, T.G.; Kim, J.S.; Kim, C.S. Apricot Kernel extract and amygdalin inhibit urban particulate matter-induced keratoconjunctivitis sicca. Molecules 2019, 24, 650. [CrossRef]

58. Ma, Q.Y.; Huang, D.Y.; Zhang, H.J.; Wang, S.; Chen, X.F. Exposure to particulate matter 2.5 (PM2.5) induced macrophagedependent inflammation, characterized by increased Th1/Th17 cytokine secretion and cytotoxicity. Int. Immunopharmacol. 2017, 50, 139-145. [CrossRef]

59. Chua, S.Y.L.; Warwick, A.; Peto, T.; Balaskas, K.; Moore, A.T.; Reisman, C.; Desai, P.; Lotery, A.J.; Dhillon, B.; Khaw, P.T.; et al. Association of ambient air pollution with age-related macular degeneration and retinal thickness in UK Biobank. Br. J. Ophthalmol. 2021. [CrossRef]

60. Kim, S.; Park, H.; Park, H.; Joung, B.; Kim, E. The acute respiratory exposure by intratracheal instillation of Sprague-Dawley rats with diesel particulate matter induces retinal thickening. Cutan. Ocul. Toxicol. 2016, 35, 275-280. [CrossRef] [PubMed]

61. Louwies, T.; Vuegen, C.; Panis, L.I.; Cox, B.; Vrijens, K.; Nawrot, T.S.; De Boever, P. miRNA expression profiles and retinal blood vessel calibers are associated with short-term particulate matter air pollution exposure. Environ. Res. 2016, 147, 24-31. [CrossRef] [PubMed]

62. Lee, H.; Hwang-Bo, H.; Ji, S.Y.; Kim, M.Y.; Kim, S.Y.; Park, C.; Hong, S.H.; Kim, G.Y.; Song, K.S.; Hyun, J.W.; et al. Diesel particulate matter 2.5 promotes epithelial-mesenchymal transition of human retinal pigment epithelial cells via generation of reactive oxygen species. Environ. Pollut. 2020, 262, 114301. [CrossRef] [PubMed]

63. Lee, H.; Kim, D.H.; Kim, J.H.; Park, S.K.; Jeong, J.W.; Kim, M.Y.; Hong, S.H.; Song, K.S.; Kim, G.Y.; Hyun, J.W.; et al. Urban aerosol particulate matter promotes necrosis and autophagy via reactive oxygen species-mediated cellular disorders that are accompanied by cell cycle arrest in retinal pigment epithelial cells. Antioxidants 2021, 10, 149. [CrossRef]

64. Ballantyne, C.M.; Podet, E.J.; Patsch, W.P.; Harati, Y.; Appel, V.; Gotto, A.M., Jr.; Young, J.B. Effects of cyclosporine therapy on plasma lipoprotein levels. JAMA 1989, 262, 53-56. [CrossRef] [PubMed]

65. Kuster, G.M.; Drexel, H.; Bleisch, J.A.; Rentsch, K.; Pei, P.; Binswanger, U.; Amann, F.W. Relation of cyclosporine blood levels to adverse effects on lipoproteins. Transplantation 1994, 57, 1479-1483. [CrossRef] [PubMed]

66. Tan, J.S.; Wang, J.J.; Flood, V.; Rochtchina, E.; Smith, W.; Mitchell, P. Dietary antioxidants and the long-term incidence of age-related macular degeneration: The Blue Mountains Eye Study. Ophthalmology 2008, 115, 334-341. [CrossRef]

67. Richer, S.; Devenport, J.; Lang, J.C. LAST II: Differential temporal responses of macular pigment optical density in patients with atrophic age-related macular degeneration to dietary supplementation with xanthophylls. Optometry 2007, 78, 213-219. [CrossRef]

68. Richer, S.; Stiles, W.; Statkute, L.; Pulido, J.; Frankowski, J.; Rudy, D.; Pei, K.; Tsipursky, M.; Nyland, J. Double-masked, placebocontrolled, randomized trial of lutein and antioxidant supplementation in the intervention of atrophic age-related macular degeneration: The Veterans LAST study (Lutein Antioxidant Supplementation Trial). Optometry 2004, 75, 216-230. [CrossRef]

69. Matossian, C.; McDonald, M.; Donaldson, K.E.; Nichols, K.K.; MacIver, S.; Gupta, P.K. Dry eye disease: Consideration for women's health. J. Womens Health 2019, 28, 502-514. [CrossRef]

70. Stapleton, F.; Alves, M.; Bunya, V.Y.; Jalbert, I.; Lekhanont, K.; Malet, F.; Na, K.S.; Schaumberg, D.; Uchino, M.; Vehof, J.; et al. TFOS DEWS II Epidemiology report. Ocul. Surf. 2017, 15, 334-365. [CrossRef]

71. McClellan, A.J.; Volpe, E.A.; Zhang, X.; Darlington, G.J.; Li, D.Q.; Pflugfelder, S.C.; de Paiva, C.S. Ocular surface disease and dacryoadenitis in aging C57BL/6 mice. Am. J. Pathol. 2014, 184, 631-643. [CrossRef]

72. Song, S.J.; Hyun, S.W.; Lee, T.G.; Park, B.; Jo, K.; Lee, I.S.; Kim, C.S. Topical application of Liriope platyphylla extract attenuates dry eye syndrome induced by particulate matter. J. Ophthalmol. 2019, 2019, 1429548. [CrossRef] 